\title{
Surgical \& Beauty Facial Masks: The New Waste Problem of Post Covid-19
}

\author{
Pierfrancesco Morganti ${ }^{1 *}$ and Gianluca Morganti ${ }^{2}$ \\ ${ }^{1}$ Academy of History of Health Care Art, Rome, Italy; China Medical University, Shenyang, China \\ ${ }^{2}$ ISCD Nanoscience Center, Rome, Italy \\ *Corresponding author: Pierfrancesco Morganti, Academy of History of Health Care Art, Rome, Italy; China Medical \\ University, Shenyang, China
}

\begin{tabular}{l} 
ARTICLE INFO \\
\hline Received: 㓞 July 08, 2020 \\
Published: 㓞 September 01, 2020 \\
\hline
\end{tabular}

Citation: Pierfrancesco M and Gianluca M. Surgical \& Beauty Facial Masks: The New Waste Problem of Post Covid-19. Biomed J Sci \& Tech Res 29(5)-2020. BJSTR. MS.ID.004878.

Abbreviations: PP: Polypropylene; PE: Polyethylene; PS: Polystyrene; PLA: Polylactic Acid; Pas: Polyhydroxy Alkenoates

\begin{abstract}
The actual unsustainable plastic waste has been further increased by the massive use of surgical- and beauty masks made prevalently by non-biodegradable petrol-derived polymers, such as polypropylene and polyethylene. It has been estimated the surgical mask market will reach US $\$ 87.67$ billion by 2027 and the beauty mask around US $\$ 8.8$ billion by 2021. This enormous quantity of waste will generate a global economic lost of US $\$ 40$ billion per year, leading to problems for the human health and the environment. As a consequence of these pollutant compounds, it is expected by 2050 that oceans will contain more plastic than fish, while the change will create further disasters worldwide. Thus, the necessity to change the actual linear economy to a circular economy by the use of recyclable plastic made by biodegradable polymers. The paper reports some data for the use of chitin nanofibrils and lignin as raw materials which, obtained from waste, may be used to produce biodegradable surgical- and beauty masks.
\end{abstract}

Keywords: Chitin Nanofibrils; Lignin; Surgical Masks; Beauty Masks; Market Masks; Plastics, Pollution; Urban Waste; Circular Economy; COVID-19

\section{Mini Review}

Plastic waste represents a great unsolved problem of the World' pollution. The annual production of plastic, used to make principally packaging's and textiles, has increased from 1.7 million metric tons in 1950 to 322 million metric tons in 2015 [1] (Figure 1). As a consequence, it has been estimated that every year 8 million metric tons of plastic waste enter into the oceans( $\sim 86 \%$ in Asia Pacific) adding to the $\sim 250$ million tons (i.e 5 trillion of microparticles) ,currently circulating on their surface (Figure 2) $[1,2]$. Additionally, the COVID-19 pandemic and the consequential demand for medical personal protective equipment (masks, gloves, and dressings) with the major use of disposal syringes, catheters, and blood bags, are further increasing this waste. On the one hand, disposable gloves and masks are also massively used from people going outside for shopping who avoid touching surfaces during the lockdown period, creating further pollution also. Surgical masks, gloves, and dressings, in fact, are made prevalently by non- biodegradable polymers, such as melt-blown polypropylene (PP) and polyethylene (PE), both produced as non-biodegradable petrolderived compounds [3]. It is just to remember that PE is the same polymer used to make plastic shopping bags which, used worldwide for years, have caused tremendous environmental issues!

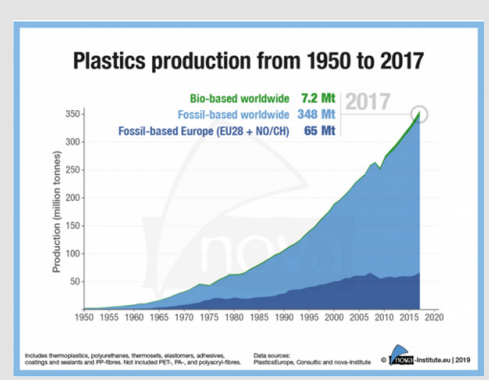

Figure 1: Worldwide production of plastics ( by courtesy of Plastic Europe [1]). 


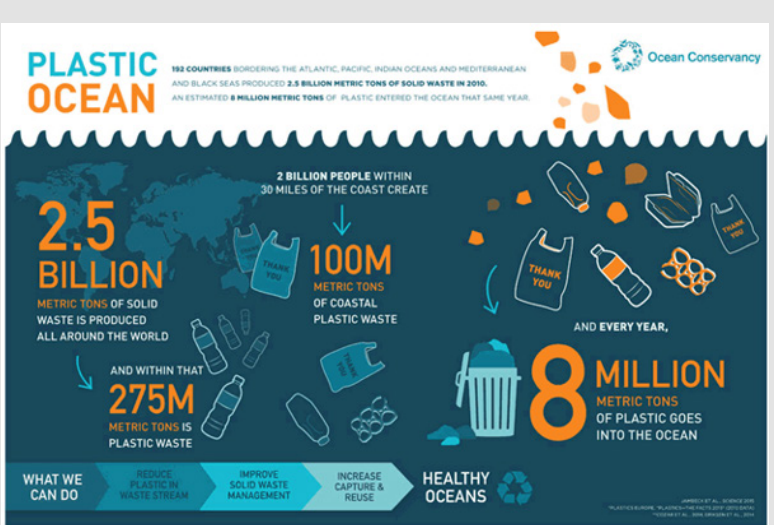

Figure 2: Worldwide production of plastics (by courtesy of plastic EU [1,2].

Moreover, before and during the lockdown period, COVID-19 pushed people to use more plastic than usual by the ordered takeaway food, packed into disposable boxes made all by the nonbiodegradable PP or Polystyrene (PS). Just as an example to better understand how large the problem of this new waste is, it has been calculated from Turin Polytechnic University that Italy, during its lifting of lockdown phase will need one billion masks and half million gloves for month. If just $1 \%$ of these masks will be disposed incorrectly and dispersed in nature, as in Hong Kong (Figure 3) [4], it would result in as 10 million masks per month, polluting the environment for more than 400 tons, considering around $4 \mathrm{~g}$ the weight of each mask! [5]. Thus, coronavirus waste has become a new form of pollution, provoking a number of unexpected impacts on the worldwide environment by the increased use of plastic. However, the positive results for the forced confinement at home during the COVID-19 pandemic, was the strong daily slowing down of the global carbon dioxide (CO2) emissions, decreased by -17\% by early April 2020 compared with the mean 2019 levels [6]. Therefore, on the one hand, it is urgent to know ,determine ,and understand which kind of actual masks should be better to select and use daily between the surgical medical device's masks and the simpler washable and reusable cloth masks.

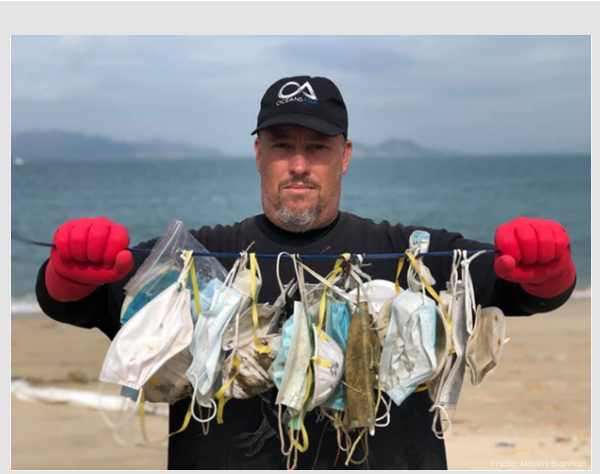

Figure 3: Surgical masks incorrectly dispersed in nature in Hong Kong (By courtesy of Monella [4]).
Both the masks, in fact, may be used from general consumers who have to be instructed on the existing differences (effectiveness, safeness ,benefits and risks) between the used tissues which could be cause of serious problems for their personal health and the environment [7]. On the other hand, there is the necessity to study and produce the COVID-19 items by the use of biodegradable natural polymers, such as chitin/chitosan, starch and lignin or natural- made, such as polylactic acid (PLA) obtained by microbial fermentation of starch/ sugarcane or polyhydroxy alkenoates (PAs) made by sugars and lipids. All these polymers are environmentally friendly because decomposed into harmless and small molecules by the action of microorganisms living in nature. Another new source of plastic waste is caused by the increased use of sheet Beauty masks made prevalently by non-biodegradable polymers. The factor driving the global demand of these smart masks is a rise in economic growth surge in consumer preferences toward innovative, natural, skin- and environment-friendly cosmetic products (Figure 4) and changing luxuring behaviors of consumers. People use these masks to remove the skin' excess oil and as moisturizing and antiaging cosmetics also because they don't want to feel old so that their use for at least one a month, is thought to maintain their own mental and physical balance [8].

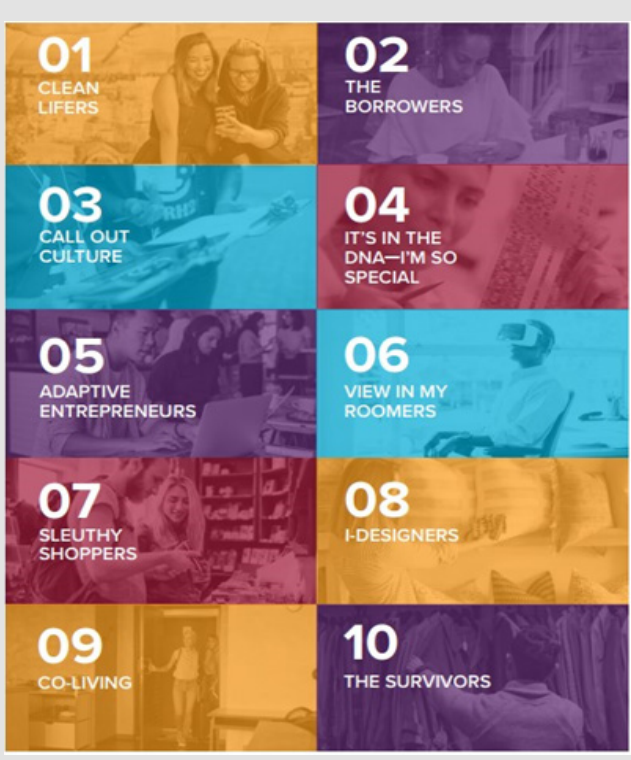

Figure 4: The 10 key consumer preferences on cosmetic products according to Euromonitor (by courtesy of Euromonitor [8]).

In conclusion on the one hand ,the single-use of surgical masks is considered indispensable especially during the COVID-19 pandemic period to protect the organism from the microbial and viruses invasion, while the of beauty masks result useful to maintain an healthy and juvenile aspect. On the other hand, it is necessary to think about the planet's long period health, by the most possible use of natural-derived polymers, such as chitin and lignin. 


\section{Surgical and Beauty Mask Market \& Waste}

\section{Surgical Masks}

Single-use Surgical Masks are medical device products that, registered worldwide at Ministry of Health of the different Countries, are classified in depending on the level of protection they provide. They are composed by a musty-layered structure, generally made by three layers where a layer of textile is covered on both sides by non-woven PP/PE melt bowed films to obtain a bacteria filtration efficiency greater than 96\% [7]. The single-use mask, available in many different styles and grades, is designed to provide protection against pathogen microorganisms filtering out air bone particles, viruses, and bacteria above 1 micron. Its filtration efficiency, that has to be controlled by standardized procedures, depends on fibers structure/cross-sectional shape and the relative manufacture. Reusable masks made from multi-layered cloth may be attractive to minimize the disposal of plastic waste. Thus, it is important to know risk associated with laundering processes necessary to eliminate contamination from fabric and linen materials. Moreover, it seems necessary to organize comparative studies on the wash ability and safeness of these masks' reusing, giving to consumers the guidelines for their correct use together with the motivations for rendering them attractive.

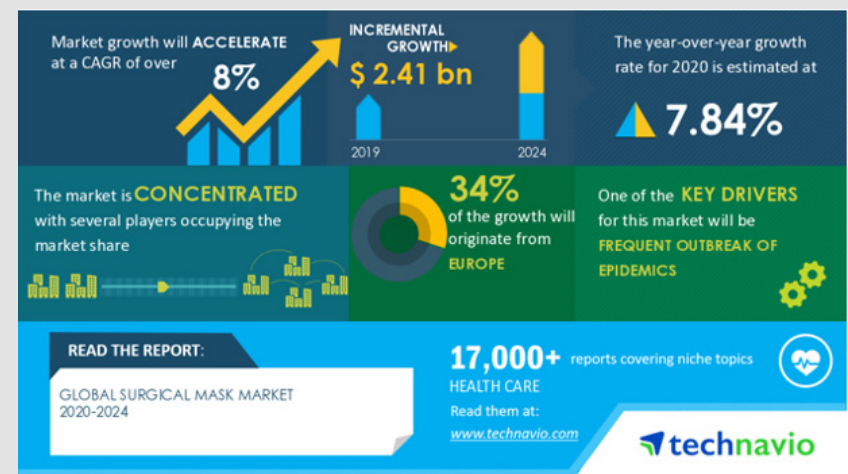

Figure 5: Surgical masks market 2020-2024 according to Technavio(by courtesy of Technavio [12]).

However, it is to underline that, according to recent scientific research studies, it seems that both the commercial surgical and cotton masks seem to be not so effective in preventing the dissemination of the SARS-COVID to the environment and external mask surface: they have shown a filtration efficiency of 53-75\% while cloth masks $28-90 \%[9,10]$. Thus, due to the impact of COVID-19 pandemic and high grow rate of the geriatric population the surgical mask market has been increased significantly and is estimated to reach US\$ 87.67 billion by 2027 from US\$ 48.60 in 2019 registering the highest CAGR of $8.1 \%$ during the forecast period 2017-2027 (Figure 5) [11,12]. Among the segment of this market, cotton(generically mixed with synthetic polymers) is presently leading the market, while non-woven face covers are primarily used in hospital (Figure 6). Thus, as previously reported, the increased use of surgical masks has aggravated the waste problem worldwide. At this purpose, the European Commission has adopted the Coronavirus Response Investment Initiative $[13,14]$. Proper waste management, in fact, is part of the EU essential services, remembering that the total annual waste European generation amounts to 5 tons per capita. This new rule is considered an important message for the management of the actual municipal waste necessary to protect the health of proper citizens and the environment, during the COVID-19 crisis [13].

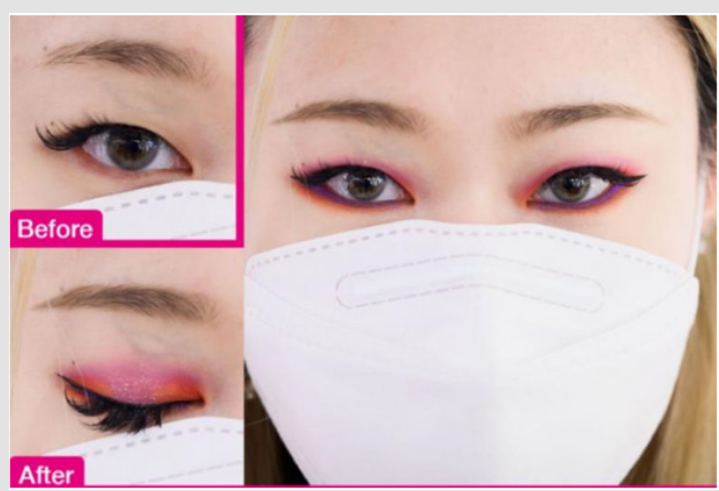

Figure 6: The COVID-19 pandemic has increased the use of eyes make-up specifically in Asia-Pacific (by courtesy of Mintel Group [16]).

\section{Beauty Facial Mask}

Wellness is, however, a modern world with ancient roots, the key tenets of which are both preventive and holistic measures from the ancient civilizations from East (India, CINA) to the West (Greece, Egypt, Rome). Actually, consumers are becoming to explore the push-pull between nature and science and cosmetics are considered essential for social wellness from both women and men of the different generations [14,15]. These consumers are searching natural products considered more efficacious with minimal toxicity, while the beauty industry is playing an essential role during the COVID19 pandemic by providing people with basic hygiene products and supporting their self-esteem [16]. Thus, an elegant surgical face mask design, for example, may be used to differentiate the facial image together with a colored make-up, enhancing brows and eyes staying on under the mask [6]. However, Fashion and beauty, have a close relationship to select the surgical mask also ,each influencing the other by color and style as well as the beauty face mask is selected for its nature less and effectiveness.

As result of a new way of living the market growth of these cosmetic masks has been evaluated differently, according also to the period of research, if performed before or after the COVID-19 pandemic. Thus, on May 2017 it was reported a booming market evaluated at US $\$ 5.7$ billion in 2016 for reaching US\$ 6.3 in 2017 and 
US\$ 8.8 by 2021 with a CAGR of $9.1 \%$ [17]. By another 2019 research study it has been expected a market of US\$ 29.4 billion by 2025 with a CAGR of $7.1 \%$ with masks used overnight for skin and mind relaxation [18]; always in 2019, it was reported a CAGR of $10.2 \%$ until 2025 for the masks used especially as a consequence of work related stress and a significant rise in pollution levels in densely populated countries, first of all in North America, Asia Pacific, and Europe [19]. Finally, a further study of 2020 has reported a market of US\$ 2.1 billion in 2018 exhibiting an incremented revenue of US $\$ 0.7$ billion from 2019,reaching US $\$ 2.9$ by 2025 with an annual CAGR of $3.7 \%$ (Figure 7) [20].

Global Face Masks Market Size, (in \$ Billion), 2018-2026

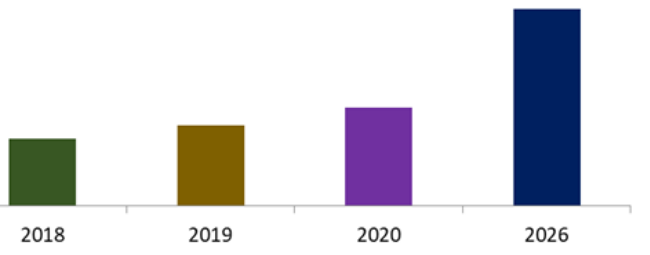

Figure 7: Cosmetic market of Beauty Face Masks( from US\$ 2.1billion in 2018 to US\$2.9 billion in 2025).

\section{Proposed Solutions}
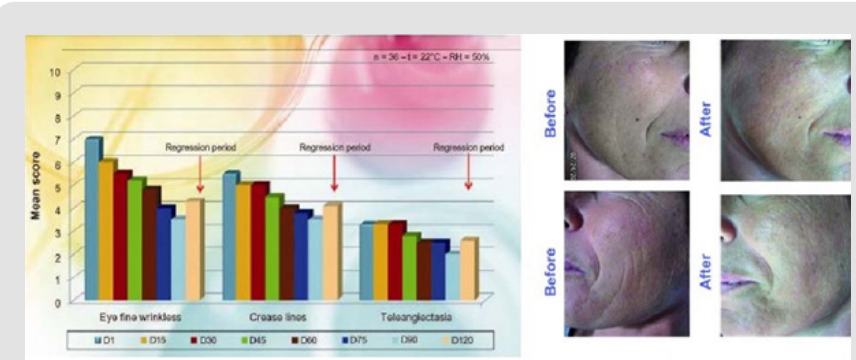

Figure 8: Anti-aging activity of the complex CN-NG.

Taking due account of consumer expectations and preferences toward innovative and natural products and remembering that plastic micro-particles go into food, soil and water with a toxic effect, it is necessary to promote the alternative use of sustainable surgical- and beauty recyclable masks made by biodegradable materials. According to the numerous research studies of our group one of the solutions appear the use of polysaccharide compounds ,such as chitin and lignin as basic raw materials embedded into natural and biodegradable, nano-composite polymers, used as nano-carrier emulsions or non-woven smart tissues [21-23]. It has been shown that these non- woven tissues, made also by watersoluble polymers, may be realized by natural fibers containing the chitin-lignin microparticle complexes, bound on its surface or into their structure [24-26]. These innovative tissues, made by waste materials result functional agents in skin regeneration and rejuvenation, according also to the United Nations' goals for the sustainable development of a new bio-green economy [27-29]. By the different active ingredients encapsulated into the $\mathrm{CN}-\mathrm{NG}$ complexes, the tissues have shown anti- aging (Figure 8), antipollution or skin repairing activity (Figure 9) and ,therefore, to be effective for their use as beauty facial sheet masks or advanced medications.

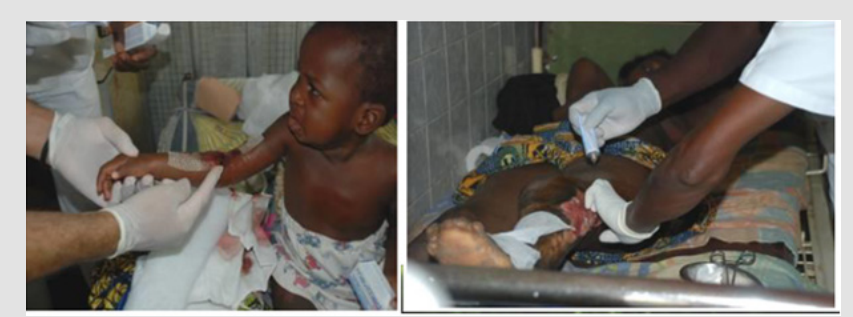

Figure 9: Skin repairing activity on wounded skin of the complex CN-NG.

These masks, if well organized by different layers of bioresorbable materials, may mimic the extracellular matrix ,being also able to filter nanoparticles and microorganisms, such as bacteria and viruses. Moreover, being free of polypropylene and other synthetic polymers, these innovative masks avoid the face' inflammation phenomena, caused by the actual distributed products [28,30-33]. On the other hand, textured and biodegradable cleansing micro emulsions, formulated by the same CN-LG carriers, could be used to wash and sanitizing the hands. At this purpose, the non-woven tissues made by our research group have evidencing in vitro and in vivo antioxidant, antibacterial, Immunomodulating and interesting healing capacities to repair lesioned tissues or rejuvenate aged and photo-aged skin, according to the differed active ingredients used [34-39]. These smart tissue-carriers, in fact, have shown to be able to load and deliver the active ingredients through the cutaneous tissue replicating its normal physiological morphology.

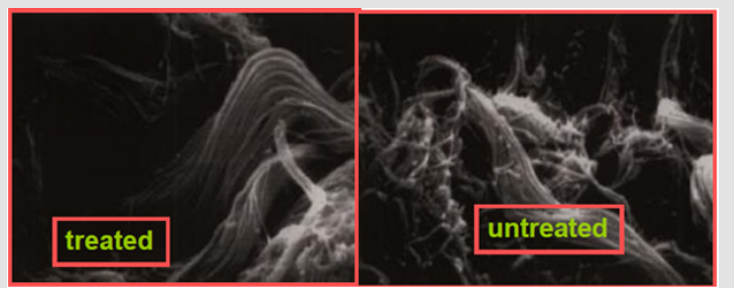

Figure 10: Right disposition of collagen fibers treated by a gel of chitin nanofibrils (by the courtesy of Tucci et al [40].

The components , such as chitin and lignin in their nano size, stimulate the production of anti-inflammatory cytokines and defensine-2 ,mimicking the native Extra Cellular Matrix (ECM) [23,35-37,40-42] and involving the right production and regular disposition of the collagen' fibers (Figure 10) [43]. Moreover, it is interesting to underline the complete biodegradability of the tissues selected which have shown to be skin- and environmentally 
friendly. They, in fact, are easily metabolized by human and the environment enzymes, to ingredients safe and utilized from the cells as food or energy [24,25].

\section{Conclusion}

The waste problem became a great problem of pollution for the entire planet. On the one hand ,plastic goods, plastic packaging, and surgical- and beauty masks are an integral part of the global economy delivering many benefits, on the other hand 95\%of their value is lost to the economy, generating negative pollutants for a value of around US $\$ 40$ billion per year $[44,45]$. Moreover, it is to remember that Increasing levels of pollutants can modify the energy balance of the atmosphere and planet' surface, leading to climate change. Thus, given the growth increasing consumption of these non-biodegradable materials, by 2050 oceans are expected to contain more plastics than fish! $[44,45]$. It is time, therefore, to change our way of producing and living going versus a circular economy, without using COVID-19 as an excuse to revive old habits by solving one problem (the mask necessity) creating another (plastic waste). By the actual technologies, in fact, it is possible to use renewable raw materials which can be recycled after use via existing recycling systems, according to the objective of the EU Single Plastic Directive for promoting use and proper management of biobased plastics by 2025 [46].

Thus, the possibility to produce and use surgical- and beauty masks and cosmetic products, made by the suggested polymers, is considered a necessity to reduce the worldwide pollution and safeguard skin health and its circadian clock, influenced by environmental factors and the modern lifestyle [23,30-39,47] Enhanced personal hygiene by the use of correct and ecosustainable products, therefore, is one of the main ways to prevent the spread of the COVID-19 $\mathrm{g}$ as well as to maintain the general beauty and health of our body and the environment.

\section{References}

1. Ritchie H, Roser M (2018) Plastic Pollution. Our World In Data.

2. Eriksen M, Lebreton LC, Carlson HS, Thiel M, Moore C, et al. (2014) Plastic pollution in the world oceans: More than 5 trillion plastic peaces weighing over 250,000 tons a float as sea. PLOS one 9(12): e111913.

3. Morganti P, Yudin VE, Morganti G, Coltelli MB (2020) Tuning up Surgical \& Beauty Masks for a Cleaner Environment. In print on Cosmetics.

4. Monella L (2020) Pollution get worse after COVID-19 pandemic? Euro News.

5. Brannan N, Stokes G (2020) Anti-virus face masks plague Hong's beaches, AFP, HKFP.

6. Le Quere' C, Jackson RB, June's MW, Smith AJP, Abernethy S, et al. Temporary reduction in daily global CO2 emissions during the COVID-19 forced confinement. Nature Climate Change 10: 647-653.

7. (2020) UCL. The Environmental Dangers of Employing Single-use Face Masks as Part of a COVID-19 Exit Strategy.

8. Angus A, Westbrook G (2020) Top 10 Global Consumer Trends. Euromonitor International, London, UK.
9. Ortega R, Gonzales M, Nozari A, Canelli R (2020) Personal Protective Equipment and COVID-19. N Engl J Med 382: e105.

10. Mueller AV, Eden MJ, Jessica J, Bellini C, Fernadez LA (2020) Comparative Method for Comparative Assessment of Particle Filtration Efficiency of Fabric Masks as Alternative to Standard Surgical Masks for PPE. medRxiv.

11. Watson J (2020) Surgical Mask Market by Type, by End-User, by Distribution Channel, forecast to 2027. Report Data.

12. (2020) Technavio. Global Disposable Respiratory Masks Market, 20182023.

13. (2020) EC, Waste Management in the Contest of the Coronavirus Crisis. Bruxelles, Belgium.

14. Badge P (2019) Beauty Survey 2019 Key Insights. Euromonitor international.

15. Jindal S, Kwek S, Mc Dougall A (2020) Personal Care Trends 2030.

16. Kwek S (2020) Face Masks fuel Post-COVID-19 Beauty opportunity. Minter Group Ltd, London, EU.

17. (2017) Core sight. The face mask market.

18. (2020) PrNewswire. Overnight Face Mask Market Size, Share \& Trends Analysis Report by Product, Region and Segment Forecasts 2019-2025.

19. (2019) Globe news wire. Global Face Masks Market 2018-2025.

20. (2020) News Wire. Global Sheet Face Masks Market 2020: Product Type, Price, Point and Distribution Channel Analysis. Portland, USA.

21. Morganti P (2019) (Ed) Bionanotechnology to Save the Environment .Plant and Fishery's Biomass as Alternative to Petrol. MDPI, Basel, Switzerland.

22. Morganti P (2020) Nano cosmetics: An introduction. In: A. Nanda, S Nanda, TA Nguyen, S Rajendran and Y Silmani (Eds.). Nano cosmetics: Fundamentals, Applications and Toxicity. Elsevier, Amsterdam, Netherlands, p. 3-16.

23. Morganti P, Chen Hong Duo, Morganti G (2020) Nanocosmetics: Future Perspective. In: A. Nanda, S Nanda, TA Nguyen, S Rayendran and Y Silmani (Eds.). Nanocosmetics: Fundamentals Applications and Toxicity, Elsevier, Amsterdam, Netherlands, pp. 455-480.

24. Morganti P, Fabrizi G, Palombo P, Palombo M, Ruocco E, et al. (2008) Chitin nanofibrils: A new active Carrier. J Appl Cosmetol 26: 113-128.

25. Morganti P, Febo P, Cardillo M, Barone A (2017) Chitin Nanofibril and Nanolignin: Natural Polymers of Biomedical Interest. Clin Cosmet Dermatol 1(2).

26. Morganti P, Coltelli MB, Danti S (2018) Chitin and Lignin to Produce Biocompatible Tissues. Res Cli Dematol 1(1): 5-11.

27. Danti S, Trombi L, Fusco A, Azimi B, Lazzeri A, et al. (2019) Chitin Nanofibrils and Nanolignin as Functional Agents in Skin Regeneraton. Int J Mol Sci 20(11): 2669.

28. Morganti P (2018) Use of Chitin nanofibrils from Biomass for an Innovative Bioeconomy. In: J Ebothe' \& W Ahmed (Eds.). Nanofabrication using Nanomaterials, 2018, One Central Press, Manchester, UK pp 1-22

29. Anad M (2016) Innovation and Sustainable Development: A Bioeconomy Perspective. United Nations Report, New Dehli, India.

30. Morganti P, Coltelli MB, Danti S (2018) Biobased Tissues for Innovative Cosmetic Products: Poly Bio Skin as an EU Research Project. Glob J Nanomedicine 3(4)

31. Morganti P, Coltelli MB (2019) A New Carrier for Advanced Cosmeceuticals. Cosmetics 6: 10 .

32. Morganti P, Morganti G, Colao C (2019) Biofunctional Textiles for Aged Skin. Biomedicines 7(3): 51. 
33. Morganti P, Morganti G, Coltelli MB (2019) Chitin Nanomaterials and Nanocomposites for Tissue Repair. In: AH Choi and B Ben-Nissan (Eds.) Marine-Derived Biomaterials for Tissue Engineering Applications, Springer Singapore, pp. 523-544.

34. Morganti P, Morganti G, Coltelli MB (2020) Skin and Pollution: The Smart Nano-based Cosmetically Tissues to Save the Planet Ecosystem. In: A Nanda, S Nanda, TA Nguyen, S Rajendran and Y Slimani (Eds.). Nanocosmetics: Fundamentals, Applications and Toxicity, Elsevier, Amsterdam, Netherlands, pp. 287-304.

35. Morganti P, Tishchenko G, Palombo M, Kelnar I, Brozova L, et al (2013) Chitin Nanofibrils for Biomimetic Products: Nanoparticles and Nanocomposites Chitosan Films in health Care. In: Se-Kwon Kim (Ed) Marine Biomaterials: Characterization, Isolation and Applications, Boca Raton, FL, USA, CRC Press, pp. 681-716.

36. Morganti P, Fusco A, Paoletti I, Perfetti P, Del Ciotto P, et al. (2017) Antiinflammatory, Immunomodulating, and Tissue Repair Activity in Human Keratinocytes of Green Nanocomposites, Materials 10(7): 843.

37. Donnarumma G, Fusco A, Morganti P, Palombo M, Aniboletti T, et al. (2018) Advanced Medications made by Green Nanocomposites. Int J Res Nano Sci 5: 261-270.

38. Tischenko G, Morganti P, Stoller P, Kelnar I, Mikesova J Kovarova J, et al. (2019) Chitin Nanofibrils-Chitisan Composite Films: Characterization and Properties. In: P. Morganti (Eds.). Bio nanotechnology to Save the Environment. Plant and Fishery's Biomass as Alternative to Petrol, Basel, Switzerland, MDPI pp. 191-226.

39. Anniboletti T, Palombo M, Moroni S, BrunoA, Palombo P, et al. (2019) Clinical Activity of Innovative Polymeric Nanoparticles and Nonwoven Tissues. In: P Morganti (Eds.). Bio nanotechnology to Save the
Environment. Plant and Fishery's Biomass as Alternative to Petrol, Basel, Switzerland, MDPI, pp. 349-360

40. Morganti P, Anniboletti T, Pollastrini C, Morganti G (2019) Natural Polymers for Body Care to Save the Environment. Biomed J Sci \& Tech Res.

41. Tucci MG, Mattioli Belmonte M, Ricotti G, Biagini G (1999) Polysaccharides: Health- Environment Binomial. J Appl Cosmetol 17: 94-101.

42. Morganti P, Palombo M, Tischchenko G, Yudin VE, Guarneri F, et al. (2014) Chitin- Hyaluronan Nanoparticles: A multifunctional carrier to deliver anti-aging active ingredients through the skin. Cosmetics 1: 149158.

43. Morganti P, Morganti G, Danti S, Coltelli MB, Donnarumma G (2020) Biodegradable Nanomaterials for Cosmetic and Medical Use. In Print on: V Kumar, P Guleria, N Dasgupta and S Ranjan (Eds.). Functionalized Nanomaterials II: Applications, CRC Press, Taylor \& Francis Group, New York, USA.

44. Sloan J, Degan B, Scelta G (2019) Frontier Technologies for Addressing Plastic Pollution. United Nations report, Department of Economic \& Social Affairs, New York, USA

45. Ellen Mc Arthur (2016) The New Plastic Economy. Rethinking the Future of Plastics \& Catalyzing Action. Ellen McArthur Foundation Report.

46. (2018) EU. Single Plastic Directive, COM (2018) 340 final, 28/52018 Bruxelles, Belgium.

47. Hettwer S, Gyenge EB, Obermayer B (2020) The skin's circadian clock. Int J Cosmet 1-7.
ISSN: 2574-1241

DOI: $10.26717 /$ BJSTR.2020.29.004878

Pierfrancesco Morganti. Biomed J Sci \& Tech Res

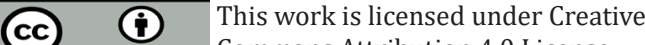

Submission Link: https://biomedres.us/submit-manuscript.php
This work is licensed under Creative Commons Attribution 4.0 License

\begin{tabular}{ll}
\hline & Assets of Publishing with us \\
\hline RESEARCHES & Global archiving of articles \\
\hline & - Immediate, unrestricted online access \\
\hline
\end{tabular}

